\title{
Prevention of Malignant Transformation of Oral Leukoplakia and Oral Lichen Planus Using Laser: An Observational Study
}

\author{
Karandeep Singh Arora ${ }^{1 *}$, Rahul Bansal ${ }^{1}$, Shreeyam Mohapatra ${ }^{2}$, Akshay \\ Verma $^{3}$, Sakshi Sharma ${ }^{4}$, Shubhangi Pareek ${ }^{5}$
}

\begin{abstract}
Objectives: The present observational study was conducted with an aim to evaluate the efficacy of diode laser in management of homogenous oral leukoplakia (OL) and reticular oral lichen planus (OLP), so that these potentially malignant disorders can be limited and further malignant transformation can be prevented. Further the assessment of associated postoperative complications after laser therapy was also carried out. Study Design: Present study was carried out using diode laser $810 \mathrm{~nm}$ on 60 subjects, of whom 30 subjects were of homogenous OL and 30 subjects were of reticular OLP aged between 20 - 60 years, the diagnosis of which was histopathologically confirmed. Results: Of the 60 subjects none complained of pain during and immediately after surgery with no bleeding at any stage of the procedure. By the end of $3^{\text {rd }}$ day post operative most subjects reported no pain and swelling and very few subjects had negligible pain and swelling when evaluated. On subsequent follow-up of 1,2 and 4 week(s) none of the subject reported of pain, swelling or bleeding and it was noted that all the areas treated with laser had healed without scarring with no signs of recurrence. Fibrosis was seen in two male patients and one female patient treated for OL and OLP respectively. Conclusion: Patient compliance and contentment without any postoperative complications were observed to be of high degree in the present study. Thus diode laser can be considered as a best alternative to conventional surgical treatment modality in managing OL and OLP and preventing its further transformation.
\end{abstract}

Keywords: Diode laser- oral leukoplakia- oral lichen planus- potentially malignant disorder- prevention

Asian Pac J Cancer Prev, 19 (12), 3635-3641

\section{Introduction}

The diode laser belongs to a group of active solid semiconductor laser which works on the principle of converting electrical energy into light energy by the use of elements such as gallium, arsenic, aluminium and indium (Akbulut et al., 2013). Light energy emitted by the diode laser (wavelength $810-890 \mathrm{~nm}$ ) is mostly absorbed by the soft tissue rather than the hard tissue structures. (Aras et al., 2010). This renders the use of these lasers in treatment of oral soft tissue lesions.

Laser intervention prevents recurrence and restricts malignant transformation, and also reduces post-operative dysfunctions. Post-laser therapy recurrence is reported as ranging from $7.7-38.1 \%$ and malignant transformation as ranging from 2.6-9\% (Ishii et al., 2003; Ishii et al., 2004).

The advantages of using laser in treatment of oral lesions includes; the haemostatic effect (giving a clear field of operation), brief therapeutic intervention, reduced traumatization of adjoining tissues (reduced inflammatory response and pain). In most of the cases healing is magnificent, when an ideal coagulation/ablation ratio is specified, with limited contraction of treated area. The only disadvantage of using laser as a treatment modality is destruction of the removed tissue, that leads to limited histopathological analysis and delayed epithelial regeneration. when compared to surgical excision with suture (Ishii et al., 2004; Vivek et al., 2008; Hamadah et al., 2009).

Considering the ease, painless procedure, minimal postoperative complications and less chances of recurrence and also the limited amount of research that assess the use of laser in management of potentially malignant disorders i.e. oral leukoplakia (OL) and oral lichen planus (OLP), the present observational research was undertaken to evaluate the efficacy and effectiveness of diode laser in the management of the same, so as to restrict these potentially malignant disorders and further malignant transformation can be prevented.

${ }^{1}$ Department of Oral Medicine and Radiology, M. M. College of Dental Sciences and Research, Mullana, Ambala, Haryana, ${ }^{2}$ Department of Oral Medicine and Radiology, SCB Dental College and Hospital, Cuttack, ${ }^{5}$ Department of Oral Pathology and Microbiology, Institute of Dental Sciences, Bhubneshwar, Odisha, ${ }^{3}$ Department of Oral Pathology and Microbiology, Rajasthan Dental College and Hospital, Jaipur, Rajasthan, ${ }^{4}$ Department of Public Health Dentistry, Bhojia Dental College and Hospital, Bhud, Baddi, Himachal Pradesh, India.*For correspondence: drkaranarora@yahoo.com 


\section{Materials and Methods}

The present study was carried out for a duration of 1 year, subsequent to the approval of the ethical committee of the institute. Patients with history of white patch/lesion were screened and selected from the routine OPD of the Department of Oral Medicine and Radiology. 60 subjects, aged 20 to 60 years, of either sex, having white patch/lesion (more than $1 \mathrm{~cm}$ and less than $4 \mathrm{~cm}$ in its greatest dimension) and histopatologically diagnosed as homogenous oral leukoplakia and reticular oral lichen planus, were included in the study. Out of these 60 subjects 30 subjects were having homogenous oral leukoplakia and 30 subjects were having reticular oral lichen planus Subjects with any other lesion in the affected area; under anticoagulants, systemic steroids and immunosuppressive drugs; diagnosed with carcinoma; having HIV; or pregnant women, were excluded from the study.

After selection of subject following clinical examination, a punch biopsy was carried out to confirm the diagnosis of homogenous oral leukoplakia and reticular oral lichen planus. Following confirmatory histopatological diagnosis the subjects underwent management using diode laser (Cheese ${ }^{\mathrm{TM}}$ Mini Dental Diode Laser Systems, Gigaa Laser, China). After following the standard protocol for safety topical anesthesia was applied over the affected site. Laser tip of 320 micro meters was used in continuous mode. The duration of application was approximately 1012 seconds per side at $3-5 \mathrm{~W}$ at a wavelength of $810 \mathrm{~nm}$ which varied according to lesion size under non-contact mode. The lesion was irradiated till the area changed to white (photocoagulation). $2 \mathrm{~mm}$ of normal mucosa along the margins was also included.

Pain was evaluated using standard visual analogue scale (VAS) i.e. scoring between 0 - 10. For swelling a score between 0 - 3 ( 0 - No Swelling; 1 - Mild Swelling; 2 - Moderate Swelling; 3 - Severe Swelling) was given. For bleeding a score between $0-3(0-$ No Bleeding; 1 - Mild Bleeding; 2 - Moderate Bleeding; 3 - Heavy Bleeding) was given. For coagulation a score between 0 -3 (0 - No Coagulation; 1 - Little Coagulation; 2-Good Coagulation; 3 - Very Good Coagulation) was given. For dysplasia a scoring between 0 - $3(0$ - No Dysplasia; 1 - Mild Dysplasia; 2 - Moderate Dysplasia; 3 - Severe Dysplasia) was given.

After successful completion of treatment all the cases were examined within first 3 days, then 1,2 and 4 week(s). The post operative complications such as pain, bleeding, swelling, functional disturbances, wound healing and recurrence were evaluated. Also any fibrosis over the site of irradiation was carefully recorded at the end of four weeks.

The clinical evaluation of the present study was divided in to 7 stages and during evaluation the scoring criteria was used. The 7 stages are as follows:

a) Before treatment: Histopathological confirmation

b) During Treatment: Evaluation of pain and coagulation.

c) Directly after Laser Treatment: Evaluation of pain and bleeding.

d) 3 days post treatment: Evaluation of post operative complications such as pain, bleeding and swelling.

e) 1 week post treatment: The same post operative complications were evaluated as that on 3rd day.

f) 2 week post treatment: Evaluation of the same post operative complications as that on 1 week post operative along with wound healing.

g) 4 week post treatment: Evaluation of wound healing along with post operative complication was carried out.

As a precautionary measure all patients were prescribed analgesics for pain and advised to take if needed. Also the patients who underwent treatment were strictly advised and counseled to abstain from use of tobacco and alcohol.

The data obtained was tabulated using Microsoft Excel and subjected to observations.

\section{Results}

Out of total $30 \mathrm{OL}$ subjects 21 were males aged between 20 - 60 years, with a mean of $41.86 \pm 11.01$ years and 9 were females aged between 35 - 60 years, with a mean of $47.22 \pm 7.34$ years, and out of 30 OLP subjects 12 were males aged between 26 - 52 years, with a mean of $43.7 \pm 9.6$ years, and 18 females, aged between $20-60$ years, with a mean age of $46.8 \pm 7.9$ years.

The clinical evaluation and observations were divided into 7 stages.

\section{Before Treatment}

All subjects underwent biopsy to confirm the diagnosis and also evaluation of dysplastic changes. On observation maximum number of subjects were having no dysplasia and a very few were mildly dysplastic (Table 1). The most common site was buccal mucosa followed by labial mucosa (Table 2).

\section{During Laser Treatment}

On observation none of the subjects felt any kind of pain during treatment. For coagulation patients showed good coagulation followed by very good coagulation (Table 3).

\section{Directly after Laser Treatment}

On evaluation none of the study group subjects felt any kind of pain directly after laser treatment. Also maximum subjects responded to laser treatment with no bleeding (Table 4).

\section{Three days post treatment}

No subjects reported with post operative bleeding. Evaluation of pain revealed that mostly the subjects had no pain and only a few reported with negligible pain (Table 5). Also most of the subjects did not report any post operative

Table 1. Evaluation of Dysplasia

\begin{tabular}{lcccc}
\hline Site & \multicolumn{2}{c}{ Oral Leukoplakia } & \multicolumn{2}{c}{ Oral Lichen Planus } \\
& $\begin{array}{c}\text { No. of } \\
\text { Patients }\end{array}$ & $\begin{array}{c}\text { Percentage } \\
\%\end{array}$ & $\begin{array}{c}\text { No. of } \\
\text { Patients }\end{array}$ & $\begin{array}{c}\text { Percentage } \\
\%\end{array}$ \\
\hline Buccal Mucosa & 22 & 73.33 & 28 & 93.30 \\
Labial Mucosa & 7 & 23.33 & 2 & 6.70 \\
Tongue & 1 & 3.34 & 0 & 0 \\
\hline
\end{tabular}




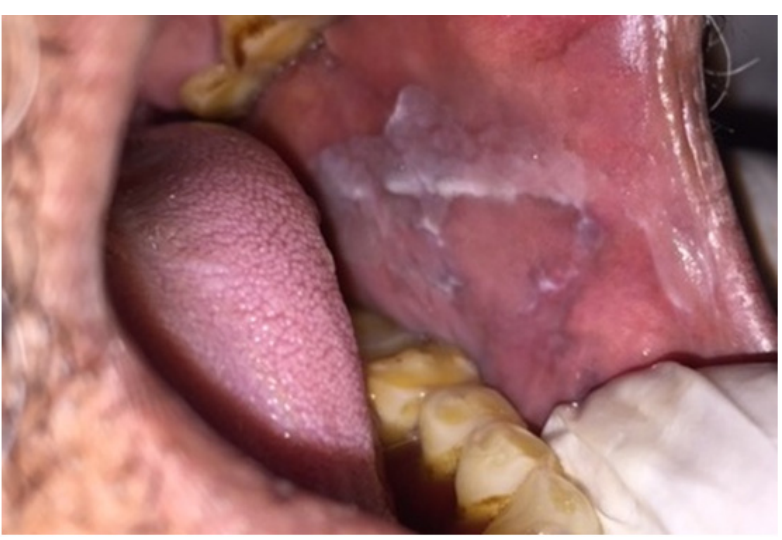

Figure 1. Clinical Presentation of Oral Leukoplakia

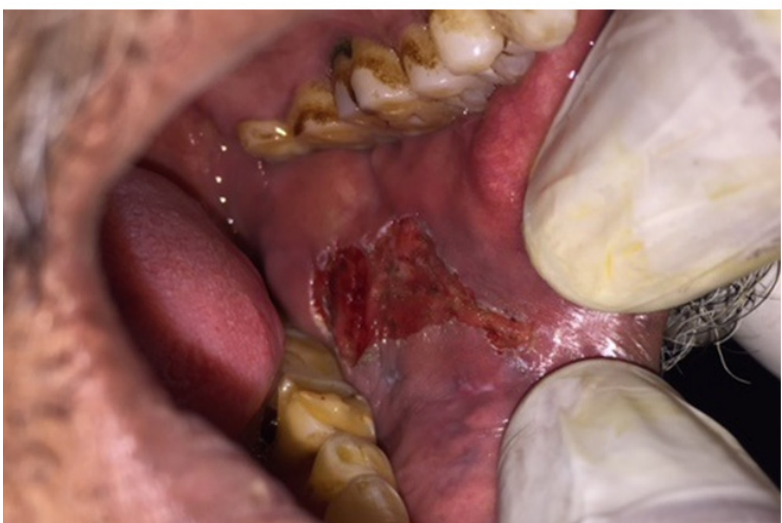

Figure 2. Immediately after Laser Treatment of Oral Leukoplakia

swelling while a few had little swelling (Table 6).

\section{One week post treatment}

On evaluation no subject had reported with post operative bleeding and swelling. But only one male subject treated for OL had pain which scored 1 (negligible)

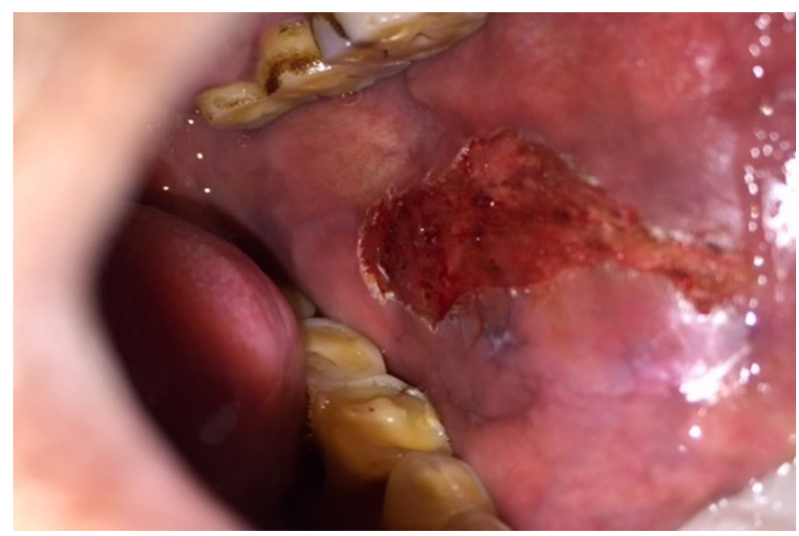

Figure 3. Three Days Post Treatment of Oral Leukoplakia

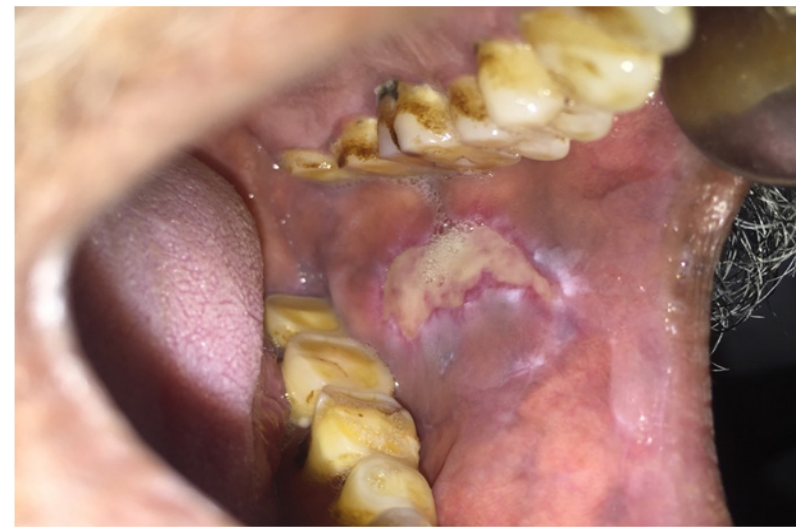

Figure 4. One Week Post Treatment of Oral Leukoplakia

on the VAS scale.

Two weeks post treatment

All the subjects did not have any post operative complications i.e. pain, bleeding or swelling. Also the wound healing appeared to be normal.

Four weeks post treatment

Table 2. Distribution of OL and OLP in Oral Cavity

\begin{tabular}{|c|c|c|c|c|c|c|c|c|c|}
\hline \multirow[t]{2}{*}{ Score $(0-3)$} & \multirow[t]{2}{*}{ Degree of Pain } & \multicolumn{4}{|c|}{ Oral Leukoplakia } & \multicolumn{4}{|c|}{ Oral Lichen Planus } \\
\hline & & \multicolumn{3}{|c|}{ No. of Patients } & Percentage $\%$ & & atients & & Percentage $\%$ \\
\hline \multirow[t]{2}{*}{0} & No Dysplasia & Males & 18 & 27 & 90 & Males & 12 & 30 & 40 \\
\hline & & Females & 9 & & & Females & 18 & & 60 \\
\hline \multirow[t]{2}{*}{2} & Mild Dysplasia & Males & 3 & 3 & 10 & Males & 0 & & 0 \\
\hline & & Females & 0 & & & Females & 0 & & 0 \\
\hline 3 & Moderate Dysplasia & 0 & & & 0 & 0 & & & 0 \\
\hline 4 & Severe Dysplasia & 0 & & & 0 & 0 & & & 0 \\
\hline
\end{tabular}

Table 3. Evaluation of Coagulation During Laser Treatment

\begin{tabular}{|c|c|c|c|c|c|c|c|c|c|}
\hline \multirow[t]{2}{*}{ Score $(0-3)$} & \multirow[t]{2}{*}{ Degree of Bleeding } & \multicolumn{4}{|c|}{ Oral Leukoplakia } & \multicolumn{4}{|c|}{ Oral Lichen Planus } \\
\hline & & \multicolumn{3}{|c|}{ No. of Patients } & \multirow{2}{*}{$\frac{\text { Percentage } \%}{76.60}$} & \multicolumn{3}{|c|}{ No. of Patients } & \multirow{2}{*}{$\frac{\text { Percentage } \%}{83.30}$} \\
\hline 0 & No Bleeding & Males & 15 & 23 & & Males & 10 & 25 & \\
\hline & & Females & 8 & & & Females & 15 & & \\
\hline \multirow[t]{2}{*}{1} & Mild Bleeding & Males & 6 & 7 & 23.40 & Males & 2 & 5 & 16.70 \\
\hline & & Females & 1 & & & Females & 3 & & \\
\hline 2 & Moderate Bleeding & 0 & & & 0 & 0 & & & 0 \\
\hline 3 & Heavy Bleeding & 0 & & & 0 & 0 & & & 0 \\
\hline
\end{tabular}


Table 4. Evaluation of Bleeding Directly after Laser Treatment

\begin{tabular}{|c|c|c|c|c|c|c|c|c|c|}
\hline \multirow[t]{2}{*}{ Score $(0-3)$} & \multirow[t]{2}{*}{ Degree of Coagulation } & \multicolumn{4}{|c|}{ Oral Leukoplakia } & \multicolumn{4}{|c|}{ Oral Lichen Planus } \\
\hline & & \multicolumn{3}{|c|}{ No. of Patients } & Percentage \% & \multicolumn{3}{|c|}{ No. of Patients } & \multirow{2}{*}{$\frac{\text { Percentage } \%}{0}$} \\
\hline 0 & No Coagulation & 0 & & & 0 & 0 & & & \\
\hline 1 & Little Coagulation & 0 & & & 0 & 0 & & & 0 \\
\hline \multirow[t]{2}{*}{2} & Good Coagulation & Males & 13 & 17 & 56.60 & Males & 9 & 19 & 66.30 \\
\hline & & Females & 4 & & & Females & 10 & & \\
\hline \multirow[t]{2}{*}{3} & Very Good & Males & 8 & 13 & 43.40 & Males & 9 & 11 & 36.70 \\
\hline & Coagulation & Females & 5 & & & Females & 8 & & \\
\hline
\end{tabular}

Table 5. Evaluation of Pain on $3^{\text {rd }}$ Day Post Treatment

\begin{tabular}{|c|c|c|c|c|c|c|c|c|c|}
\hline \multirow[t]{2}{*}{ Score (VAS scale) } & \multirow[t]{2}{*}{ Degree of Pain } & \multicolumn{4}{|c|}{ Oral Leukoplakia } & \multicolumn{4}{|c|}{ Oral Lichen Planus } \\
\hline & & \multicolumn{3}{|c|}{ No. of Patients } & Percentage $\%$ & & tients & & Percentage $\%$ \\
\hline \multirow[t]{2}{*}{0} & \multirow[t]{2}{*}{ No Pain } & Males & 19 & 25 & \multirow{2}{*}{83.30} & Males & 12 & 27 & \multirow{2}{*}{90} \\
\hline & & Females & 6 & & & Females & 15 & & \\
\hline \multirow[t]{2}{*}{1} & \multirow[t]{2}{*}{ Negligible Pain } & Males & 2 & 5 & \multirow{2}{*}{16.70} & Males & 0 & 3 & \multirow{2}{*}{10} \\
\hline & & Females & 3 & & & Females & 3 & & \\
\hline
\end{tabular}

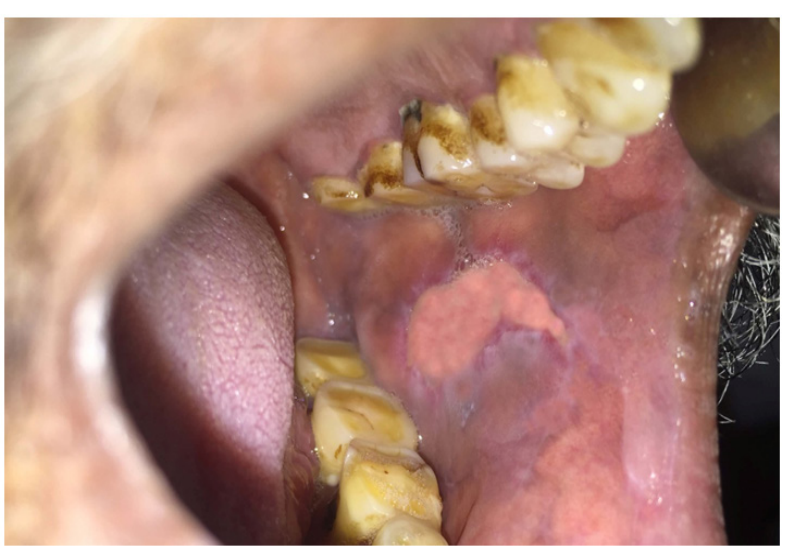

Figure 5. Two Weeks Post Treatment of Oral Leukoplakia

All the post operative complications were re-evaluated and were found to be satisfactory. Further, on evaluating the site for signs of fibrosis we observed that the lesion healed with fibrosis in 2 male patients treated for OL and 1 female patient treated for OLP. No recurrence of either OL or OLP was observed.

\section{Discussion}

Oral leukoplakia (OL) is the most frequently seen pre-neoplastic lesion, clinically classified into homogenous and non-homogenous leukoplakia. It is often

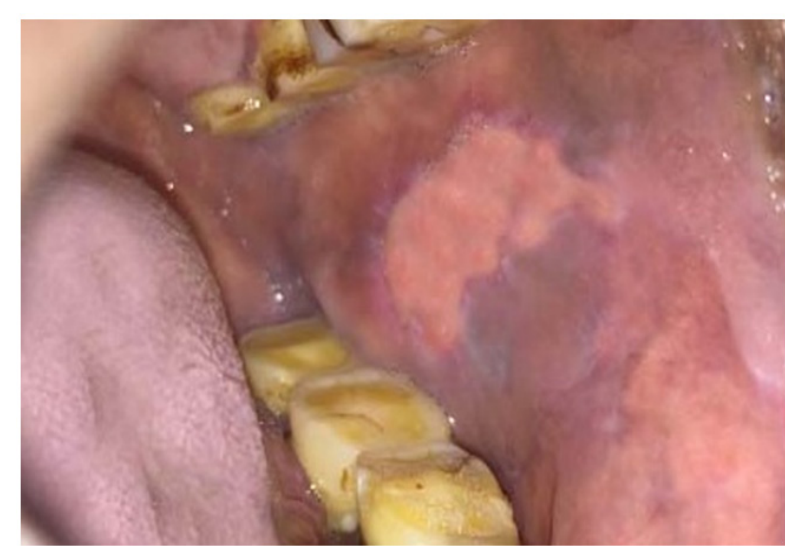

Figure 6. Four Week Post Treatment of Oral Leukoplakia

related to tobacco addiction, and almost $80 \%$ of patients are smoker. Clinically it is seen as a white lesion of more than $5 \mathrm{~mm}$ diameter, which is non-scrapable. It is more prevalent in males than females. Approximately $70 \%$ of OL lesions are found on the buccal mucosa, vermillion border of lower lip and on gingiva (Amagasa et al., 1979; Warnakulasuriya et al., 2007).

It has also been reported that the localization of OL is found on gingiva, and other sites such as tongue, buccal mucosa, the floor of the mouth and palatal mucosa in decreasing order, while that on the lip is rare (Amagasa et al., 2011; Kazaoka et al., 1990).

Table 6. Evaluation of Swelling on $3^{\text {rd }}$ Day Post Treatment

\begin{tabular}{|c|c|c|c|c|c|c|c|c|c|}
\hline \multirow[t]{2}{*}{ Score $(0-3)$} & \multirow[t]{2}{*}{ Degree of Swelling } & \multicolumn{4}{|c|}{ Oral Leukoplakia } & \multicolumn{4}{|c|}{ Oral Lichen Planus } \\
\hline & & \multicolumn{3}{|c|}{ No. of Patients } & \multirow{2}{*}{$\frac{\text { Percentage } \%}{63.30}$} & \multicolumn{3}{|c|}{ No. of Patients } & \multirow{2}{*}{$\frac{\text { Percentage } \%}{96.60}$} \\
\hline 0 & No Swelling & Males & 13 & 19 & & Males & 12 & 29 & \\
\hline & & Females & 6 & & & Females & 17 & & \\
\hline \multirow[t]{2}{*}{1} & Mild Swelling & Males & 8 & 11 & 36.70 & Males & 0 & 1 & 3.70 \\
\hline & & Females & 3 & & & Females & 1 & & \\
\hline 2 & Moderate Swelling & 0 & & & 0 & 0 & & & 0 \\
\hline 3 & Severe Swelling & 0 & & & 0 & 0 & & & 0 \\
\hline
\end{tabular}


Prevalence of OL has been reported differently in various studies varying from 1.55 to $3.28 \%$ in three different districts in India (Pindborg et al., 1968), $3.1-6.2 \%$ in three different districts of Papua New Guinea (Pindborg et al., 1968), 11.7\% in Indians (Silverman et al., 1976), $2.89 \%$ in white Americans (Bouquot and Gorlin, 1986), and 2.5\% in Japanese (Ikeda et al., 1991).

A lesion that occurs subsequently at the primary site after treatment is considered as recurrence. Recurrence occurs from remnants of white plaque, which remains even after treatment, which can grow and increase in size afterwards (Horch et al., 1986). This was the reason that in the present study along with the white patch $2 \mathrm{~mm}$ of surrounding mucosa was also removed to lower the chances of recurrence.

Oral Lichen Planus (OLP) is considered to be a chronic immunological inflammatory disease clinically classified into 6 types (reticular, papular, plaque type, atrophic, erosive and bullous), with few of its types associated with pain or burning sensation. It has been reported to be more prevalent in females than males. The most common management of OLP includes topical or systemic steroids and sometimes both, which are well known for their side effects and contra-indications. Moreover, this treatment is prolonged and has patient dependency. So, there pitfalls can be overcome by the use of laser therapy (Abraham and Lankupalli, 2014; Raval et al., 2011; Reddy et al., 2015; Soliman et al., 2005).

Sometimes, conventional surgical management of OL and also OLP may become difficult. Most common problem encountered is bleeding (because of rich vascularization of oral structures). Another problem is large extensive lesions, which leave large post-operative defects. In such cases defects need to be covered with different flaps or mucosa or even skin graft. In both cases a longer operation and second intervention (donor site) need to be considered. It also causes post-operative complications like edema or pain and also tissue scar formation after healing is more pronounced, which may lead to functional disturbances (e.g. limitation of mouth opening). By the use of laser we can avoid these inconveniences of conventional surgery (Bögözi and Bocskay, 2011).

For the management of lesions pertaining to the oral soft tissues, diode lasers are preferred because their penetration depth is based on wavelength i.e. from $2-3 \mathrm{~mm}$ and the mode of delivery is with a fibro-optic cable using a hand piece in pulse or continuous mode. Its cutting efficacy is more of optical than thermal which provides a clean cutting edge, bloodless field of view and minimal scarring (Raval et al., 2011).

Laser surgery is advantageous for the patient and the surgeon. It controls hemorrhage during and after procedure and provides better visibility of operating field. Also there is minimal damage to adjoining structures and reduces postoperative complications and chances of infection. Histopathological features reported from studies carried out for wound healing post laser treatment show few myofibroblasts, suggesting to be effector of wound contraction (Chu et al., 1988; Frame, 1985; Ishii et al., 2003; Pinheiro and Frame, 1996; Roodenburg et al., 1991; Rossmann et al., 1994).
However, laser surgery has its own disadvantages. First disadvantage is that a pre-operative biopsy need to be performed, secondly, epithelial regeneration is delayed and wound takes more time to re-epithelialize, third being safety precautions during laser procedure both for patient and operator (Chu et al., 1988; Frame, 1985).

In the present study, $810 \mathrm{~nm}$ diode laser was opted mainly because of its ease of use, treating large areas in single application and precise control. The depth of penetration is more with diode laser thus it completely ablates the epithelium owing to minimal chance of recurrence. Thus advantages like fine cutting ability and the tolerable damage zone with increased depth of penetration clearly shows the effectiveness of diode laser.

In the present study no recurrence was observed for $\mathrm{OL}$ or OLP, which is in contradiction to the study conducted by Ravan et al., (2011) in which 10 patients of OL and OLP were treated and recurrence was observed in 2 cases.

In a somewhat similar research carried out by Lalabonova et al., (2012) on 17 patients diagnosed with OL and treated using Nd-YAG, showed complete healing by the end of 4 th week with no post operative complication. Their findings are very well in accordance with the present study.

Akbulunt et al., (2013) in their study evaluated the effects of the same diode laser in 27 patients including 5 patients of OL and 5 patients of OLP and reported no complications, with complete healing of lesions by the end of 2 nd week and 4 th week respectively. Their findings are completely in agreement with the present study where complete healing of OL and OLP was observed by the end of $4^{\text {th }}$ week.

In our study all the patients accepted the laser surgery very well and it was operator friendly with no postoperative complications, this statement is in accordance to the study carried out by Syed et al., (2009) for evaluation of CO2 laser in excision of OL. The only difference being the type of laser used in both the studies, but both gave a positive and promising result.

The results of the present study are in harmony with the study carried out by Trehan and Taylor (2004) who also concluded that non-erosive OLP deemed fair responders to laser therapy treatment.

The present study is in partial disagreement with the study conducted by Kollner et al., (2003) who concluded that out of 8 patients treated for OLP, 2 showed complete recurrence, where as in our study no recurrence of OLP was observed. Passeron et al., (2004) carried out a short study on four patients and observed that there was recurrence in three cases. The reason for recurrence in both the cases can be justified by the difference in the type of laser being used in the previous studies.

In our study it was observed that all the subjects showed signs of healing with no scarring by the end of 4th week post-operative. These findings are in concurrence with previous studies by Deppe et al., (2007), Raval et al., (2011) and Romanos et al., (1999), where all the authors concluded that they observed favorable healing with no scarring after the use of diode laser for treating pre-malignant lesions.

It was observed that during treatment of OL and

Asian Pacific Journal of Cancer Prevention, Vol 193639 
OLP using diode laser none of the patients showed no coagulation, rather the coagulation was good which gave a bloodless working condition (Deppe and Horch, 2007; Goharkhay et al., 1999; Kende et al., 2011; Romanos and Nentwig, 1999).

Previously authors have compared different types of lasers in treatment of OL. One such study was conducted by Sarkar et al., (2015) who compared diode laser and Er, Cr; YSGG laser and observed that pain was minimal, hemostasis was favorable and wound healing was good with no post-operative complications when diode laser was used while, Er, Cr; YSGG laser caused slight discomfort to patient, profuse bleeding during procedure. This was one of the reasons that we chose to use diode laser instead of any other laser.

In the present study it was noted that diode laser showed excellent wound healing without any scarring. Also in relation to hemostasis diode laser was found to be superior and gave a bloodless field of view while operating with no post-operative bleeding. In regard to pain diode laser caused no pain during surgery, directly after surgery and also on subsequent follow-up. Though few patients reported with pain and swelling but it was negligible. Thus through this study it is justified to say that diode laser which is portable, easy to handle and less expensive serves as an excellent tool for treatment of homogenous OL and reticular OLP, and these conditions can be successfully treated and their malignant transformation can be prevented without any post-operative complications and oral dysfunction.

Thus it is concluded that $810 \mathrm{~nm}$ diode lasers have a positive outcome and do serve as a reliable and successful alternative treatment modality over conventional surgical treatment of OL and OLP without any post-operative complications and without compromising the health and function of the patient. It is also advocated that further studies would be rewarding if a larger sample size and other types of OL and OLP, be included and a long term follow-up is made to determine the incidence of any recurrence or malignant transformation so that, diode laser can be made a novel therapeutic approach for management of OL and OLP.

\section{References}

Abraham RJ, Lankupalli AS (2014). Laser management of intraoral soft tissue lesions-a review of literature. IOSR $J$ Dent Med Sci, 13, 59-64.

Akbulut N, Kursun ES, Tumer MK, Kamburoglu K, Gulsen U (2013). Is the $810 \mathrm{~nm}$ diode laser the best choice in oral soft tissue therapy?. Eur J Dent, 7, 207-11.

Amagasa T, Masuo K, Fujii E, Michi K, Saito K (1979). Clinical and histopathologic study of oral leukoplakia. Relationship between clinical type and histopathologic structure. J Stomatol Soc Jpn, 46, 30-42.

Amagasa T, Michi K, Saito K, Ueno T (2011). Clinical classification of oral leukoplakia. Jpn J Oral Maxillofac Surg, 23, 89- 96.

Aras MH, Goregen M, Gungormuş M, Akgul HM (2010). Comparison of diode laser and Er:YAG lasers in the treatment of ankyloglossia. Photomed Laser Surg, 28, 173-7.

Bögözi B, Bocskay I (2011). The use of surgical lasers in the treatment of oral leukoplakia. Acta Medica Marisiensis, $\mathbf{5 7}, 578-80$

Bouquot JE, Gorlin RJ (1986). Leukoplakia, lichen planus, and other oral keratoses in 23,616 white Americans over the age of 35 years. Oral Surg, 61, 373-81.

Chu FWK, Silverman Jr S, Dedo HH (1988). CO laser treatment of oral leukoplakia. Laryngoscope, 98, 125-30.

Deppe H, Horch HH (2007). Laser applications in oral surgery and implant dentistry. Lasers Med Sci, 22, 217-21.

Frame JW (1985). Removal of oral soft tissue pathology with the CO2 laser. J Oral Maxillofac Surg, 43, 850-5.

Goharkhay K, Moritz A, Wilder-Smith P, Schoop U, Kluger W (1999). Effects on oral soft tissue produced by a diode laser in vitro. Lasers Surg Med, 25, 401-6.

Hamadah O, Thomson PJ (2009). Factors affecting carbon dioxide laser treatment for oral precancer: A patient cohort study. Lasers Surg Med, 41, 17-25.

Horch HH, Gerlach KL, Schaefer HE (1986). CO 2 laser surgery of oral premalignant lesions. Int J Oral Maxillofac Surg, 15, 19-24

Ikeda N, Ishii T, Iida S, Kawai T (1991). Epidemiological study of oral leukoplakia based on mass screening for oral mucosal diseases in a selected Japanese population. Com Dent Oral Epid, 19, 160-3.

Ishii J, Fujita K, Komori T (2003). Laser surgery as a treatment for oral leukoplakia. Oral Oncol, 39, 759-69.

Ishii J, Fujita K, Munemoto S, Komori T (2004). Management of oral leukoplakia by laser surgery: relation between recurrence and malignant transformation and clinicopathological features. J Clin Laser Med Surg, 22, 27-33.

Kazaoka Y, Nakayama K, Yoshida K, Takai Y, Fukaya M (1990). Clinico-pathological study on oral leukoplakia. Jpn J Oral Maxillofac Surg, 36, 90-5.

Kende P, Gaikwad R, Yuwanati M, Jain B (2011). Application of Diode laser in oral biopsy: Removal of white patch over tongue - A case report. J Indian Dent Assoc, 5, 985-7.

Kollner K, Wimmershoff M, Landthaler M, Leutner HU (2003). Treatment of oral lichen planus with the 308-nm UVB excimer laser--early preliminary results in eight patients. Lasers Surg Med, 33, 158-60.

Lalabonova H, Peycheva S, Petrov P (2012). Application of $\mathrm{Nd}-$ Yag laser treatment for oral leukoplakia. $J I M A B, \mathbf{1 8}$, 240- 42.

Passeron T, Zakaria W, Ostovari N, et al (2004). Treatment of erosive oral lichen planus by the $308 \mathrm{~nm}$ excimer laser. Lasers Surg Med, 34, 205.

Pindborg JJ, Barmes D, Oedpete B (1968). Epidemiology and histology of oral leukoplakia and leukoedema among Papuans and New Guineans. Cancer, 22, 379-84.

Pindborg JJ, Jolst O, Renstrup G, Roed-Petersen B (1968). Studies in oral leukoplakia: a preliminary report on the period prevalence of malignant transformation in leukoplakia based on a follow-up study of 248 patients. J Am Dent Assoc, 76, 767-71.

Pinheiro ALB, Frame JW (1996). Surgical management of premalignant lesions of the oral cavity with the $\mathrm{CO}_{2}$ laser. Braz Dent $J, 7,103-8$.

Raval N, Rama Raju D, Athota A, Reddy TY (2011). Diode laser and white lesions: a clinical study on postoperative recovery, depth control and wound healing. J Ind Acad Oral Med Radiol, 23, 308-11.

Reddy Kundoor VK, Patimeedi A, Roohi S, et al (2015). Efficacy of diode laser for the management of potentially malignant disorders. J Lasers Med Sci, 6, 120-3.

Romanos G, Nentwig GH (1999). Diode laser (980 nm) in oral and maxillofacial surgical procedures: Clinical observations based on clinical application. J Clin Laser Med Surg, 17, 
193-7.

Roodenburg JLN, Panders AK, Vermey A (1991). Carbon dioxicide laser surgery of oral leukoplakia. Oral Surg Oral Med Oral Pathol, 71, 670-4.

Rossmann JA, Brown RS, Hays GL, Lusk SS (1994). Carbon dioxide laser surgical therapy for the management of oral leukoplakia: a case report. Tex Dent $J, \mathbf{1 1 1}, 17-21$.

Sarkar S, Kailasam S, Iyer VH (2015). Effectiveness of diode laser and Er, Cr:YSGG laser in the treatment of oral leukoplakia-A comparative study. Dentistry, 5, 274.

Silverman Jr S, Bhargava K, Mani NJ, Smith LW, Malaowalla AM (1976). Malignant transformation and natural history of oral leukoplakia in 57,518 industrial workers of Gujarat, India. Cancer, 38, 1790-5.

Soliman M, Ahmed EL, Saafan A (2005). Management of oral lichen planus using diode laser $(980 \mathrm{~nm})$. A clinical study. Egypt Dermatol Online J, 1, 1-3.

Syed TF, Thukral N (2009). $\mathrm{CO}_{2}$ laser surgery for the excision of leukoplakia: A comparison with the traditional technique. J Oral Laser App, 9, 213-8.

Trehan M, Taylor CR (2004). Low-dose excimer 308-nm laser for the treatment of oral lichen planus. Arch Dermatol, 140, 415-20.

Vivek V, Jayasree RS, Balan A, Sreelatha KT, Gusta AK (2008). Three-year follow-up of oral leukoplakia after neodymium: yttrium aluminium garnet (Nd:YAG) laser surgery. Lasers Med Sci, 23, 375-9.

Warnakulasuriya S, Newell W, Vander Waal I (2007). Nomenclature and classification of potentially malignant disorders of the oral mucosa. J Oral Pathol Med, 36, 575-80.

\section{(c) (1) (8)}

This work is licensed under a Creative Commons AttributionNon Commercial 4.0 International License. 